\title{
Plasma Retinol, Thyroid Stimulating Hormone and Zinc as Predictors of Bone Mineral Density Status
}

\author{
Shawkia S. A. El-Sherbeny ${ }^{*}$, Effat A. A., Afifi ${ }^{* *}$, Wafaa M. A. Saleh ${ }^{* *}$, Asmaa, M. \\ Abdallah $^{* * *}$, Lobna M. S. Hadidy ${ }^{* * * *}$. \\ *Nutritional Biochemistry Department. National Nutrition Institute. \\ ${ }^{* * *}$ Food hygiene Department. National Nutrition Institute \\ **** Clinical Nutrition Department. National Nutrition Institute. \\ ${ }^{* * * * *}$ Nutritional Requirement and growth Department National Nutrition Institute
}

\begin{abstract}
Background: Conflicting results on the association between serum retinol level and bone mineral density (BMD) have been published. Thyroid hormones are essential for skeletal development and have direct effect on bone formation and resorption. Bone has one of the highest concentrations of zinc of all tissues, and has been shown to release zinc during deficiency for soft tissue metabolism. Objective: The objective of this study was to assess the relation between plasma levels of retinol, thyroid stimulating hormone (TSH) \& zinc and BMD of Egyptian adolescents and adults. Method: The study was a part of a cross sectional national survey conducted by National Nutrition Institute. The sample was a multistage stratified random. Target individuals were classified into two age groups (10- $\leq 18$ and $28-\leq 59$ years). Bone mineral density and plasma levels of retinol, TSH and zinc were determined. Results: Low and high plasma retinol levels were more prevalent among osteoporotic adolescent and adult males respectively than in normal subjects.. The reverse was observed in adult females. Bone mineral density correlated negatively with plasma retinol level in adult males and females and positively in adolescent males, while among females the association was significant $(\mathrm{P}=$ 0.030) and stronger. The highest deficiency of TSH was found among adult and adolescent osteoporotic males, followed by osteopenic adult males and adolescent females. Highly statistically significant difference $(\mathrm{P}<0.001)$ existed between osteoporotic and normal adult males concerning TSH deficiency. The prevalence of zinc deficiency ranged from 5.7\% to $9.5 \%$ for all target individuals. Plasma $\mathrm{Zn}$ levels were correlated negatively with bone mineral density in adult males and females. Conclusion: The results of this study reflects the controversy on the association of plasma retinol and BMD. However, the predominant finding revealed that both low and high plasna retinol levels compromise bone health. Bone status and thyroid function support the adverse effect of hyperthyroidism upon either bone osteoporosis or osteopenia and subsequently upon fracture risk. Plasma zinc deficiency correlated negatively with BMD in adult osteoporotic men.
\end{abstract}

Key words: Human BMD. Osteoporosis. Osteopenia. Fractures Plasma. Retinol. TSH. Zinc

\section{Introduction}

Osteoporosis is a complex, multifactorial condition characterized by reduced bone mass and impaired micro-architectural structure, leading to an increased susceptibility to fractures. In spite of being a geriatric disease, it has an adolescent onset so nutrition, environment and life style early in life play an important role in the development and maintenance of bone mass as well as prevention and management of osteoporosis (Kawahara et al., 2002).

Normal bone growth and development require adequate levels of vitamin A. Both low and high doses of vitamin A may 
contribute to the development demineralization of bone and development of osteoporosis. Therefore, for prevention or treatment of osteoporosis, it is best to obtain vitamin A from food sources and not to eat more than the recommended dietary allowance (RDA) (Milstone and Leachman, 2001). Previous epidemiological studies conducted on retinol supplemented subjects showed an association between high serum levels or dietary intake of retinol and risk of osteoporotic hip fracture (Maggio et al., 2006). Furthermore, Michaelsson et al. (2003) reported a U-shaped curve for blood levels of serum retinol and the risk of fractures. However, Ballew et al. (2001) found no relationship between blood levels of vitamin A and BMD.

Thyroid hormones are essential for skeletal development. They exert an important action on bone remodeling and their excess is associated with increased bone turnover, affecting bone resorption more than bone formation with net loss of bone and hence reduction in BMD (Boelaert and Franklyn, 2005). Thyroid stimulating hormone, TSH per se inhibits markers of bone resorption by osteoclast (Sun et al., 2006). In hyperthyroidism, bone remodeling is accelerated and activities of boneforming osteoblasts and boneresorbing osteoclasts are disproportionately increased leading to a net loss of $10 \%$ of mineralized bone per remodeling cycle (David et al., 2003; Boelaert and Franklgn, 2005). As thyrotoxicosis is one of the established causes of osteoporosis, Subclinical thyrotoxicosis or excessive $\mathrm{T}_{4}$ replacement therapy for hypothyrodism increases the risk of fracture (Bauer et al., 2001).

Zinc (Zn) is an essential trace mineral that is necessary for normal collagen synthesis and mineralization of bones (Wallwork and Sandstead, 1990). Zn deficiency results in impaired DNA synthesis and protein metabolism, which lead to negative effects on bone formation. The role of zinc in bone formation is well documented in animal models (Yamaguchi, 1998) and reduced serum or plasma zinc concentra- tions and increased urinary zinc excretion have also been reported in women with osteoporosis (Gur et al., 2002).

However, after long research, no national data has been found for the association between plasma TSH, retinol or zinc levels and osteoporosis in Egypt. The present study is a cross-sectional statistical one to focus on this relation among Egyptian adolescents and adults for early detection, intervention and prevention of osteoporosis.

\section{Subjects and Methods:}

\section{1-Subjects:}

Data obtained from the National Survey (cross sectional study) for the Determination of Bone Mass Density among Adolescents and Adults in Egypt conducted by the National Nutrition Institute (2004) were used in the present study.

The sample was a multistage stratified random sample selected from 6 governorates (Cairo, Dakahlia, El-Beheira, Sohag and Red Sea) representing different geographical areas in Egypt. The age of adolescents ranged from $10-\leq 18$ years, while it ranged from $28-\leq 59$ years for adults.

\section{2-Measument of Bone mineral density (BMD)}

Diagnosis of osteoporosis is currently based on the level of target individual's BMD compared with the average peak BMD of young adult Caucasian and expressed as T-score using WHO (1998) criteria, as shown in table (1). Cut off points of peak bone mass were $0.735-0.740 \mathrm{gm} / \mathrm{cm}^{2}$ for males and $0.635-0.640 \mathrm{gm} / \mathrm{cm}^{2}$ for females.

BMD was measured by dual-energy $\mathrm{x}$-ray absorptiometry (DEXA) bone desitometer (Norland Medical System, Inc,1998), which acts peripherally on calcareous bone.

Osteoporosis and severe osteoporosis cases were considered as one group in the presentation of this study.

As bone mass is in a dynamic states during adolescence and bone formation 
reaches its peak bone mass at early adulthood around 20 years. So there is no reference bone density for adolescents. Thus in this study, the reference BMD of adults recommended by WHO (1998) is used under the term relative osteopenia and relative osteoporosis during adolescence.

\section{3-Biochemical measurements:}

Sub samples of target individuals separated plasma was stored at $-20^{\circ} \mathrm{C}$ for subsequent analysis. Vitamin A (1122 samples) was measured according to $\mathrm{WHO} / \mathrm{U}$ NICEF (1994) and Bieri et al (1979). TSH (1144 sample) was determined by Elisa using kits EHTSN 969 as descr-ibed by Spencer (1995). Plasma zinc conc-entration (1438samples) was determ-ined by atomic absorption spectrometer (Unicam 929) after protein precipitation with trichloroacetic acid using the method of Smith et al. (1979).

Cut off points of the estimated parameters are 20-80 ug/dl; 0.39-6.16 mIU/L and 70-150 ug/dl for retinol, TSH and zinc respectively.

\section{4-Statistical analysis:}

It was performed using Chi-Square and pearson correlation according to Kirkood and Sterne (2003).

\section{Results:}

Mean plasma levels of retinol of target individuals was shown in Figure 1.

Plasma retinol deficiency Table, 2 was more prevalent among osteoporotic cases than normal subjects, in male adolescents $(28.2 \%$ versus $23.7 \%)\left(\chi^{2}=0.511 \mathrm{P}\right.$ $>0.05)$ and male adults $(21.9 \%$ versus $18.4 \%)\left(\chi^{2}=0.355 \mathrm{P}>0.05\right)$ respectively. The reverse was observed in females, as plasma retinol deficiency was more prevalent in normal subjects than in osteopenic adolescents and osteoporotic adults (23.9\% versus $14.6 \%)\left(\chi^{2}=1.632 \mathrm{P}>0.05\right)$ and $(19.7 \%$ versus $14.3 \%)\left(\chi^{2}=0.689 \mathrm{P}>0.05\right)$ with insignificant difference.

High plasma retinol level, (Table 2) was more prevalent among osteoporotic cases than normal subjects $(7.7 \%, 4.5 \%)$ and $(9.4 \%, 4.4 \%)$ for male adolescents and adults respectively. Concerning female adolescents, the prevalence was higher among osteopenic cases than normal $(8.3 \%, 3.3 \%)$ respectively. On the contrary, the lowest prevalence of high retinol level in adult females was found among osteoporotic cases then increased gradually in osteopenic and normal subjects $(3.6 \%, 5.3 \%$ and $8.4 \%)$ respectively.

Some participants with condition characteristics that might affect the measured items or BMD were excluded from correlations.

BMD correlated negatively with plasma retinol level in adult males $(\mathrm{R}=-$ $0.013 \mathrm{P}=0.853 \mathrm{~N}=195)$ and females $(\mathrm{R}=$ $0.075 \mathrm{P}=0.218 \mathrm{~N}=268$ ) and positively in adolescents $(\mathrm{R}=+0.007 \mathrm{P}=0.921 \mathrm{~N}=$ 215) males, while the association was significant and stronger in females $(\mathrm{R}=$ $+0.142 \mathrm{P}=0.030 \mathrm{~N}=234$ ).

The mean plasma TSH levels of studied individuals was explained in Figure 2.

Table 3 showed that in adolescents males, prevalence of TSH deficiency was $11.8 \%$ and $7.1 \%$ for osteoporotic and osteopenic males respectively versus $7.6 \%$ of normal. Among osteopenic females, TSH deficiency was $9.6 \%$ against $6.4 \%$ for normal subjects, osteopenic females was only 3 targets so, they can not be statistically evaluated. There was no significant difference between TSH values of male and female adolescents in relation to BMD. For adults, the highest percent of TSH deficiency $(13.8 \%$ and $9.9 \%)$ was found among osteoporotic and osteopenic males respectively. Among females $6.6 \%$ and $4.7 \%$ of osteopenic and osteoporotic respectively had TSH deficiency, while $8.1 \%$ and $6.7 \%$ of normal males and females respectively were TSH deficient. There was highly significant difference $\left(\chi^{2}=42.4 \quad \mathrm{P}<0.001\right.$ $\mathrm{df}=1$ ) between osteoporotic and normal adult males. However, no significant differences were observed between other groups.

The mean plasma zinc levels of studied individuals was explained in figure (3). 
Table 4 showed that highest prevalence of plasma zinc deficiency was found among osteopenic adult males $(9.1 \%)$ and adolescent females $(8.7 \%)$ respectively, followed by percentages of $6.9 \%, 6.8 \%$ and $6.1 \%$ for osteopenic \& osteoporotic adolescent males and osteopenic adults males respectively. However, no cases of osteoporosis or osteopenia were detected in adult females.

Plasma Zn levels were correlated negatively with bone mineral density in male $(\mathrm{R}=-0.023, \mathrm{P}=0.718, \mathrm{~N}=257)$ and female $(\mathrm{R}=-0.058, \mathrm{P}=0.318, \mathrm{~N}=224)$ adults.

Table (1): World Health Organization criteria for the diagnosis of osteoporosis.

\begin{tabular}{|c|c|}
\hline Category & $\begin{array}{c}\text { Criteria } \\
\text { (expressed as T-score) }\end{array}$ \\
\hline Normal & BMD $\leq 1$ SD \\
\hline Osteopenia & $>-1$ SD BMD $\geq-2.5$ SD \\
\hline Osteoporosis & BMD $<-2.5$ SD \\
\hline $\begin{array}{c}\text { Sever (Established) } \\
\text { Osteoporosis }\end{array}$ & BMD $<-2.5$ SD \\
\end{tabular}

Figure (1): Mean plasma retinol levels of target individuals in relation to Bone mineral density (BMD)
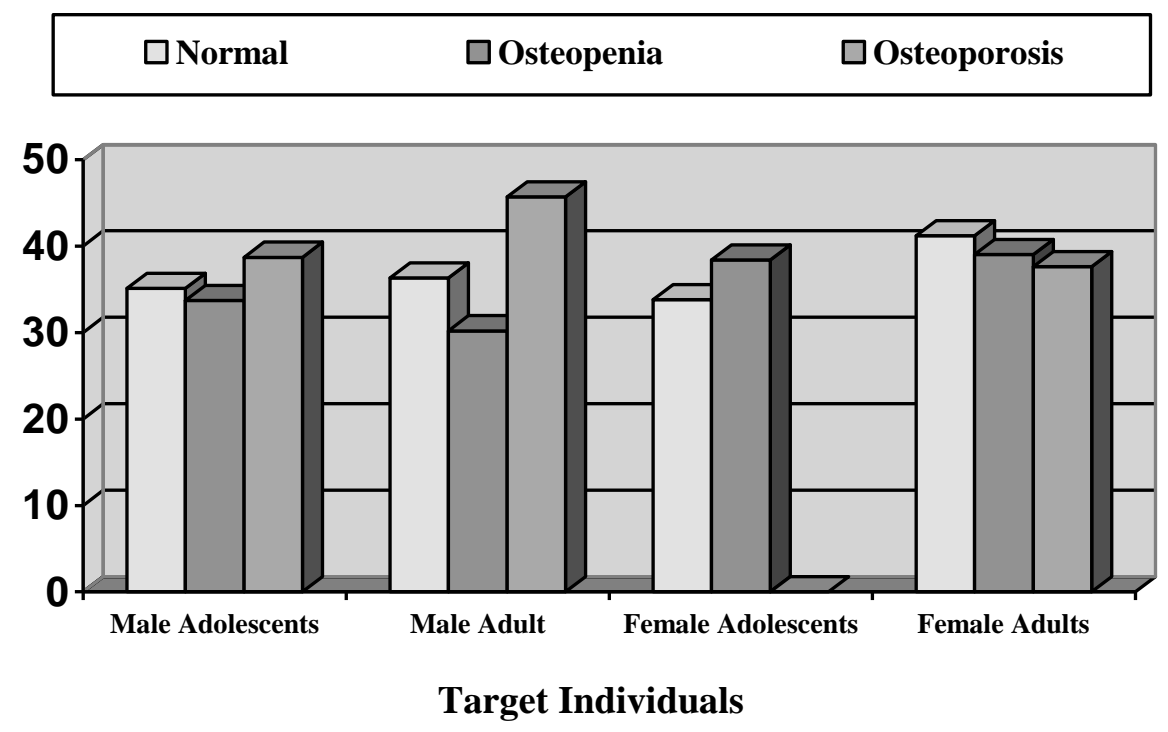
Table (2): Percent Distribution of Plasma retinol Levels of Target Individuals in Relation to Bone Mineral Density in The Total Sample.

\begin{tabular}{|c|c|c|c|c|}
\hline Target & $\begin{array}{l}\text { Cut off levels } \\
\text { (ug/dl) }\end{array}$ & Normal & Osteopenia & Osteoporosis \\
\hline \multirow{4}{*}{ Male Adolescents } & $<20$ & 23.7 & 17.8 & 28.2 \\
\hline & $20-80$ & 71.8 & 78.1 & 64.1 \\
\hline & $>80$ & 4.5 & 4.1 & 7.7 \\
\hline & Total Number & 198 & 73 & 39 \\
\hline \multirow{4}{*}{ Male Adults } & $<20$ & 18.4 & 22.2 & 21.9 \\
\hline & $20-80$ & 77.2 & 74.1 & 68.8 \\
\hline & $>80$ & 4.4 & 3.7 & 9.4 \\
\hline & Total Number & 228 & 27 & 32 \\
\hline \multirow{4}{*}{$\begin{array}{c}\text { Female } \\
\text { Adolescents }\end{array}$} & $<20$ & 23.9 & 14.6 & 0 \\
\hline & $20-80$ & 72.8 & 77.1 & 0 \\
\hline & $>80$ & 3.3 & 8.3 & 0 \\
\hline & Total Number & 276 & 48 & 0 \\
\hline \multirow{4}{*}{ Female Adults } & $<20$ & 19.7 & 21.1 & 14.3 \\
\hline & $20-80$ & 71.4 & 73.7 & 82.1 \\
\hline & $>80$ & 8.4 & 5.3 & 3.6 \\
\hline & Total Number & 294 & 19 & 28 \\
\hline
\end{tabular}

Figure (2): Plasma TSH levels of Target Individuals in Relation to Bone Mineral Density

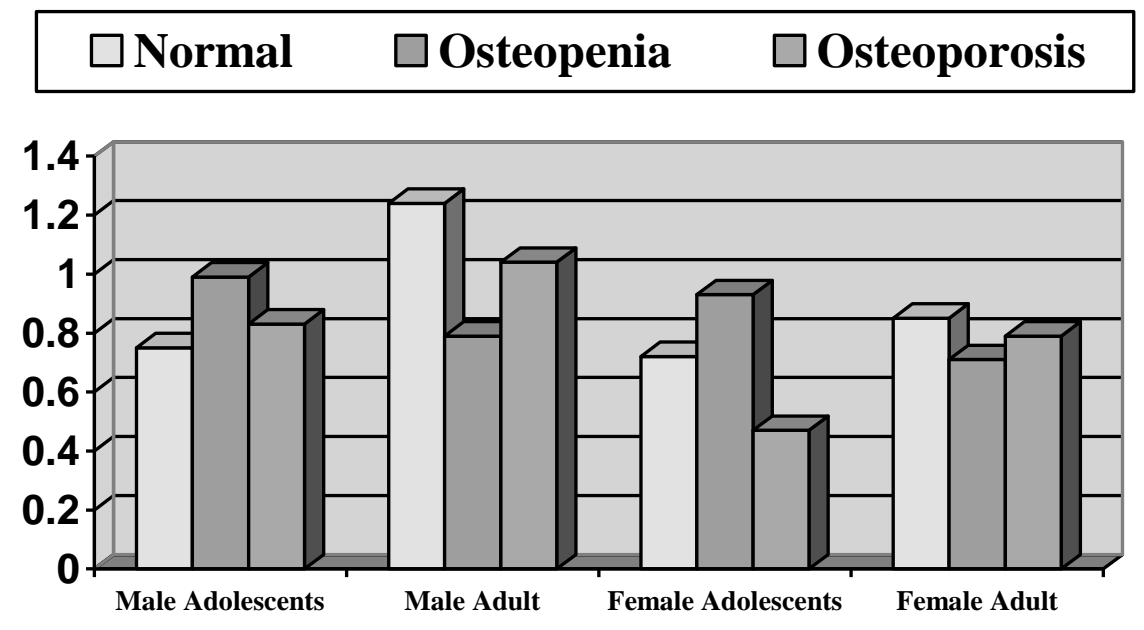

Target Individuals 
Table (3): Percent Distribution of Plasma TSH Levels of Target Individuals in Relation to Bone Mineral Density in The Total Sample.

\begin{tabular}{|c|c|c|c|c|}
\hline Target & $\begin{array}{l}\text { Cut off levels } \\
\text { (mIU/L) }\end{array}$ & Normal & Osteopenia & Osteoporosis \\
\hline \multirow{4}{*}{ Male Adolescents } & $<0.39$ & 7.6 & 7.1 & 11.8 \\
\hline & $0.39-6.16$ & 92.3 & 92.5 & 87.2 \\
\hline & $>6.16$ & 0.2 & 0.3 & 1 \\
\hline & Total Number & 178 & 82 & 27 \\
\hline \multirow{4}{*}{ Male Adults } & $<0.39$ & 8.1 & 9.9 & $13.8^{*}$ \\
\hline & $0.39-6.16$ & 91.3 & 90.1 & 85.3 \\
\hline & $>6.16$ & 0.6 & 0 & 0.9 \\
\hline & Total Number & 220 & 22 & 30 \\
\hline \multirow{4}{*}{$\begin{array}{c}\text { Female } \\
\text { Adolescents }\end{array}$} & $<0.39$ & 6.4 & 9.6 & 0 \\
\hline & $0.39-6.16$ & 93.3 & 88 & 100 \\
\hline & $>6.16$ & 0.3 & 2.4 & 0 \\
\hline & Total Number & 222 & 46 & 3 \\
\hline \multirow{4}{*}{ Female Adults } & $<0.39$ & 6.7 & 6.6 & 4.7 \\
\hline & $0.39-6.16$ & 92.6 & 93.4 & 95.3 \\
\hline & $>6.16$ & 0.7 & 0 & 0 \\
\hline & Total Number & 265 & 17 & 29 \\
\hline
\end{tabular}

$* \mathrm{P}<0.001$

Figure (3): Plasma Zinc Concentrations of Target Individuals in Relation to Bone Mineral Density

\begin{tabular}{|ll|}
\hline 日Normal & OOsteopenia \\
\hline
\end{tabular}

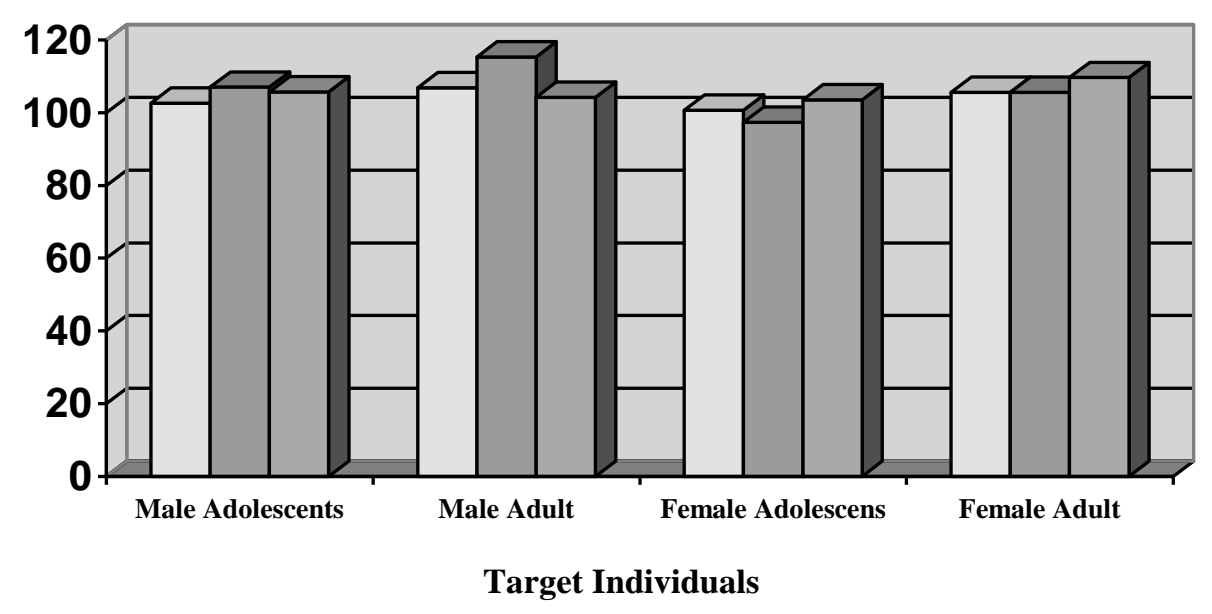


Table (4): Percent Distribution of Plasma Zinc Levels of Target Individuals in Relation to Bone Mineral Density in The Total Sample.

\begin{tabular}{|c|c|c|c|c|}
\hline \multirow{3}{*}{ Target } & $\begin{array}{c}\text { Cut off levels } \\
\text { (ug/dl) }\end{array}$ & Normal & Osteopenia & Osteoporosis \\
\hline \multirow{4}{*}{ Male Adolescents } & $<70$ & 8.3 & 6.9 & 6.8 \\
\cline { 2 - 5 } & $70-150$ & 90.1 & 87.8 & 93.2 \\
\cline { 2 - 5 } & $>150$ & 1.6 & 5.3 & 0 \\
\cline { 2 - 5 } & Total Number & 192 & 131 & 44 \\
\hline \multirow{3}{*}{ Male Adults } & $<70$ & 5.7 & 6.1 & 9.1 \\
\cline { 2 - 5 } & $70-150$ & 90.6 & 84.8 & 90.9 \\
\cline { 2 - 5 } & $>150$ & 3.7 & 9.1 & 0 \\
\cline { 2 - 5 } & Total Number & 297 & 33 & 0 \\
\hline \multirow{3}{*}{ Female } & $<70$ & 9.5 & 8.7 & 100 \\
\cline { 2 - 5 } & $70-150$ & 87.6 & 89.9 & 0 \\
\cline { 2 - 5 } & $>150$ & 2.9 & 1.4 & 0 \\
\cline { 2 - 5 } & Total Number & 242 & 69 & 5 \\
\hline \multirow{3}{*}{ Female Adults } & $<70$ & 6.0 & 0 & 40 \\
\cline { 2 - 5 } & $70-150$ & 89.3 & 100 & 0 \\
\cline { 2 - 5 } & $>150$ & 4.8 & 0 & 0 \\
\cline { 2 - 5 } & Total Number & 336 & 8 & 0 \\
\hline
\end{tabular}

\section{Discussion:}

The increased prevalence of high retinol levels in normal subjects than osteoporotic and osteopenic cases are in accordance with Maggio et al. (2006) as they found that plasma levels of retinol were consistently lower in osteoporotic than in normal women. However, Feskanish and others in 2002 recorded that intake of preformed retinol was associated with the risk of hip fracture among postmenopausal women who were not taking hormone replacement therapy (HRT), while Rejnmark et al. (2004) showed no association between intake of vitamin $\mathrm{A}$ and BMD of the femoral neck or lumbar spine. Neither did BMD differ between those 5\% Danish perimenopausal women who had the highest and those 5\% who had the lowest vitamin A intake.

On the other hand, deficiency in males agreed with Michaelsson et al. (2003) as they reported a U shaped curve for serum retinol and the risk of fracture in elderly men of Sweden. The risk is primarily associated with the highest quintiles, although to a lesser extent, risk of fracture increased in the lower quintiles of serum retinol as well.

The low prevalence of retinol deficiency in osteoporotic and osteopenic adult and adolescents females as compared with the normal are in accordance with Ballew et al. (2001) as they found no relationship between blood levels of vitamin $\mathrm{A}$ and $\mathrm{BMD}$ in Americans in the Third National Health and Nutrition Examination Survey (NHANES-III). While Maggio et al. (2006) mentioned that plasma levels of retinol tested in non-supplemented elderly women with or without severe osteoporosis were consistently lower in osteoporotic than in control women.

The results of high plasma retinol levels in the present study go in line with Penniston and Tanumihardjo (2006) as they mentioned that osteoporosis and hip frac- 
ture are associated with preformed vitamin A intakes that are only twice the current recommended dietary allowances (RDA). To control vitamin A deficiency large therapeutic doses are administered in developing countries to women and children who often are undernourished. Nevertheless, little attention has been given to the short term kinetic (i.e, after absorption but before storage) of a large dose of vitamin A or to the short and long term effects of such a dose given to lactating women on serum and breast-milk concentrations of retinol and its metab-olites. Assessing vitamin A status in persons with subtoxicity or toxicity is complicated because serum retinol concentrations are non sensitive indicators in this range of liver vitamin A reserves.

Because BMD is relatively stable between the ages of 20 and 50, there are relatively few studies evaluating the effect of the measured items (of the present study) on bone health during young and middle adulthood.

Overt hyperthyroidism results in reduction in $\mathrm{BMD}$, where bone remodeling is accelerated, leading to a net loss of $10 \%$ of mineralized bone per remodeling cycle (David et al. 2003).

Our results showed that almost $14 \%$ and $12 \%$ of osteoporotic adult and adolescent males respectively was deficient in $\mathrm{TSH}$, about $5 \%$ of adult females was also deficient. Highly significant difference was found between osteoporotic and normal adult regarding TSH deficiency, this findings agreed with Sun et al. (2006), who reported that low TSH levels correlate with increased fracture risk. Increased incidence of fracture femur by $1.8 \%$ fold was reported amongst women with previous hyperthyroidism followed a large prospective study (Boelaert and Franklyn, 2005). In accordance with these findings, another study reported increased fracture incidence rate ratio $(1.26-2.29)$ around the time of diagnosis of hyperthyroidism (Vestergaard and Mosekilde, 2002) Also, a prospective cohort study, revealed that hyperthyroidism conferred a 2-fold increase in risk of hip fracture (Bauer et al., 2001). Although thyroid hormones stimulate both the osteoblastic and osteoclastic activity, their effects are much stronger on osteoclasts leading to osteopenia and the risk of repeated bone fracture in hyperthyroid patients (Zehra et al., 2004).

Among studied osteopenic individuals, about $10 \% \& 7 \%$ of adult and adolescent males and $10 \% \& 6.6 \%$ of adolescent and adult females respectively were TSH deficient.

Like overt hyperthyroidism, subclinical hypethyroidism has been implicated in the development of osteoporosis (Boelaert and Franklyn, 2005).

In the present study, detectable percent $(7.6 \% \& 8.1 \%)$ of adolescents and adults males and $(6.4 \% \& 6.7 \%)$ of adolescents and adults females respectively were deficient in TSH. This may be because TSH deficiency in this group is not yet associated with bone complication to be manifested.

Decrease in TSH may be due to primary hyperthyroidism or over replacement of thyroid hormone in treatment of hypothyroidism (Fischbach, 2000).

The high prevalence of zinc deficiency in adult males observed in the present study was consistent with Hyun et al. (2004) as they found that plasma zinc concentrations were lower in men with osteoporosis than in their matched normal control. Moreover, Li et al. (2005) reported that lack of zinc intake levels in the meal of elderly people was correlated with BMD. However, Relea et al. (1995) found no significant differenced in zinc concentration of osteoporotic postmenopausal women with osteoporosis than those without osteoporosis.

In animals, $\mathrm{Zn}$ deficiency has been associated with abnormalities in bone growth, bone formation, and mineralization. A significant positive correlation between human bone zinc content and bone strength suggests that zinc may play a role in bone health (Yamaguchi, 1998).

Finally it may be concluded that both low and high levels of retinol compromise bone health. Bone status and thyroid status 
support the adverse effect of hyperthyroidism upon bone either osteoporosis or osteopenia. Plasma zinc deficiency correlated with BMD to some degree.

\section{Recommendations}

Vitamin A must be taken from natural food sources in adequate amount and its supplementation to women and children should be reevaluated. Further studies are needed to evaluate the importance of hyperthyroidism \& sub-clinical hyperthyroidism in terms of osteoporosis risk and to unravel the potential role of zinc in osteoporosis. Furthermore, the next studies should focus on the association between nutrition, environment and osteoporosis.

\section{References:}

1. Ballew C, Bowman B A, Sowell AL and Gillespie C (2001): Serum retinol distributions in residents of the United States: Third National Health and Nutrition Examination Survey, 1988-1994. Am. J. Clin. Nutr. 73: 586-593.

2. Bauer DC, Ettinger B, Nevitt MC and Stone KL (2001): Risk for fracture in women with serum levels of thyroid stimulating hormone. Ann Intern. Med. 134: 561-658.

3. Bieri JG, Tolliver BS and George $\mathbf{L}$ (1979): Simultaneous determination of $\alpha$ tocopherol and retinol in plasma or red blood cell by high pressure liquid chromatography. Am. J.Clin. Nutr. 32:2143-2149.

4. Boelaert K and Franklyn JA. (2005): Thyroid hormone in health and disease. $\mathrm{J}$. Endocrin. 187: 1-15.

5. David AS, Clare BH., Anthea JS., Patrick JO., Joonna C.B. and Barnard JC. et al (2003): Thyroid hormone activates fibroblasts growth factor receptor-I in bone. Molecular Endocrinology 17(9): 1751-1766.

6. Feskanish D, Singh V, Willer W $\mathrm{C}$ and Colditz G A. (2002): Vitamin A intake and hip fractures among postmenopausal pausal women. JAMA 287:47-54.

7. Fischbach F (2000): A manual of laboratory diagnostic tests. Sixth edition. Copyright 2000 by Lippincott Williams \& Wilkins, Philadelphia, Paltimor New York.
8. Gur A, Colpan L, Nas K, Cevik R, Sarac J, Erdogan F and Duz M Z. (2002): The role of trace minerals in the pathogenesis of postmenopausal osteopor-osis and a new effect of calcitonin. J. Bone Miner. Metab. 20: $39-43$.

9. Hyun $\mathbf{T} \mathbf{H}$, Barrett-Commor $\mathbf{E}$ and Milne DB (2004): Zinc intakes and plasma concentrations in men with osteop-orosis: the Rancho Bernardo Study. Am. J. Clin. Nutr. 80:715-721.

10. Kawahara TN, Krueger DC, Engrlke J A, Harke JM and Binkley NC (2002): Short term vitamin A supplem-entation does not affect bone turnover in men. J. Nutr. 132:1169-1172.

11. Kirkood B R and Sterne JAC (2003): Essential medical statistics. Second Edition Part B\&C. Puplished by Blackwell Science Ltd. Blackwell Puplishing company.

12. Li W, Tian $\mathbf{Y}$, Song $\mathbf{X}$, Zhang $M$ and Shen $G$ (2005): Relationship between $\mathrm{BMD}$ and $\mathrm{Zn}, \mathrm{Cu}, \mathrm{Ca}$ levels in the hair and meal in elderly people. J. Huazhong Univ. Sci. Technology Med. Sci. 25 (1): 97-99.

13. Maggio D, Polidori M C, Baraban M, Tafi A, Ruggiero C, Cecchetti R, Aisa MC, Stahl W and Cherubini A (2006): Low levels of carotinoid and retinol in involutional osteoporosis: A service of the National library of medicine and the National Institute of Health. Pub. Med. Bone 38 (2): 244-248.

14. Michaelsson $\mathbf{K}$, Lithell $\mathbf{H}$, Vessby $\mathbf{B}$ and Melhus H (2003): Serum retinol levels and the risk of fracture. New England Journal of Medicine., 348: 287-294.

15. Milstone $L$ and Leachman SA (2001): Do retinoids cause osteoporosis ? In Nutritional aspects of osteoporosis. Ed. Peterr Burckhardt; Bess Dawson-Hughes \& Robert P. Heaney Academic Press. USA. Chapter 25: 285-293.

16. Norland Medical System, Inc, (1998): White plains S.;N.Y.USA potla ${ }^{\mathrm{TM}}$ Dexa Bone Resitometer Console Operator's guide.

17. Penniston $\mathbf{K} \mathbf{L}$ and Tanumihardjo SA. (2006): The acute and chronic toxic effects of vitamin. Am. J. Clin. Nutr. 83 (2): 191201.

18. Rejnmark I, Vestergaars, $\mathbf{P}$, Charles $\mathbf{P}$, Hermann A, Brot $C$, Eiken $P$ and Mosekilde L (2004): No effect of vitamin A intake on bone mineral density and fracture risk in perimenopausal women. J. 
Osteoporosis International Medicine 15 (11): 872-880.

19. Relea P, Revilla M, Ripoll E, Arribas I, Villa LF and Rico H (1995): Zinc, biochemical markers of nutrition and type 1 osteoporosis. Age Ageing 24: 303-307.

20. Smith Z C, Butrimorits GP and Purdy WC (1979): Direct measurement of zinc in plasma by atomic absorption spectroscopy. Clin. Chem. 25: 1467-1491.

21. Spencer EA (1995): Clinical chemistry. Inter-laboratory/ intermetric. Assay of thyrotropin (TSH) and impact on reliability of measurement of subnormal concentrations of TSH. Clin. Chem.41: 367- 369

22. Sun L, Terry F D, Harry CB, Elsuko A.B.E. and Mone Z. ( 2006): TSH and bone loss. Annals of New York Academy of Science vol. 1068 p, 309.

23. Vestergaard $P$ and Mosekilde L (2002): Fracture in patients with hyperthyroidism and hypothyroidism; a nationwide followup study in 16249 patients. Thyroid 12: 411-419.
24. Wallwork J C and Sandstead H H. (1990): Zinc. In: Simmons DJ, ed. Nutrition and bone development. New York: Oxford University Press,:316-39.

25. WHO (1998): Definition of osteoporosis and related terms in: Guidelines for preclinical evaluation and clinical trials in osteoporosis. WHO library cataloguing in publication data. Geneva, 3: 5-25.

26. WHO/UNICEF (1994): Joint statement to XVI AVACG meeting participants. In report of XVI International vitamin A consultative group Meeting 24-28 04. Chiang Bai Thailand.

27. Yamaguchi $M$ (1998): Role of zinc in bone formation and bone resorption. J. Trace. Elem. Exp. Med. 11:119-35.

28. Zehra A, Huseyin I, Gnul C, Merih B, Pelin A, Ergun L, Glcay E and Sema A. (2004): The effect of sub-clinical thyroid dysfunction and L- thyroxin treatment on spinal bone mineral density in clinical euthyroid goitrous children. Turkish J. of Endocrinology and Metabolism 8 (4): 129134.

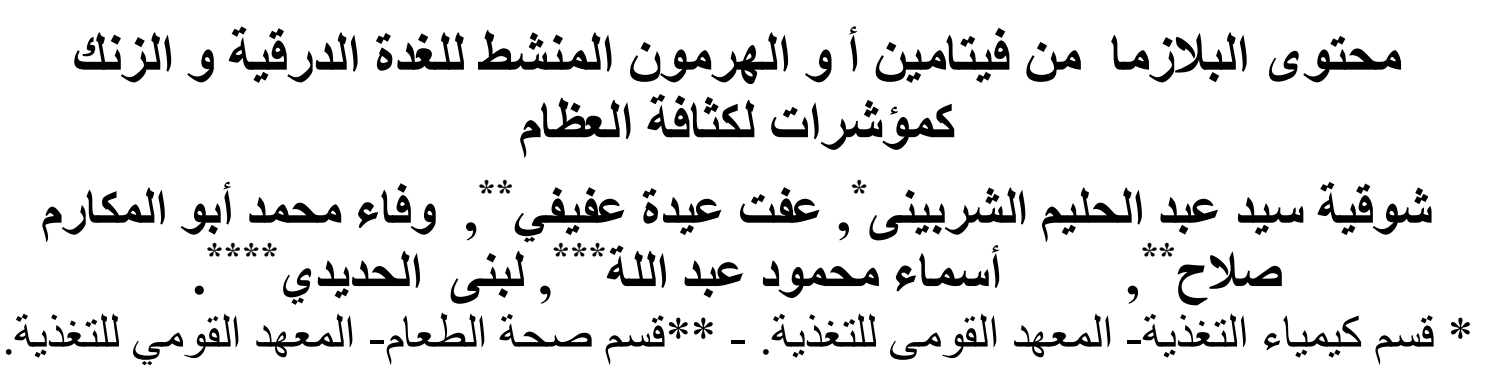


_***قم التغذية الاكلينيكيةـ المعهد القومي للتغذية. _****قم الدر ـاسات و البحوث الميدانية- المئية المعهد القومي للتغذية.

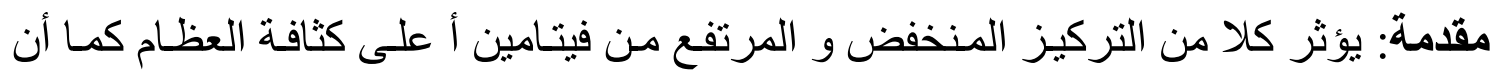

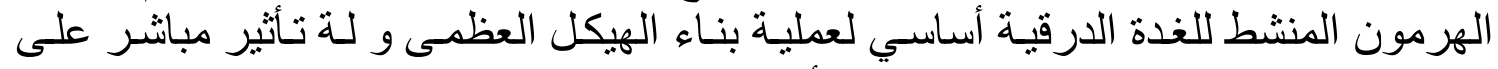

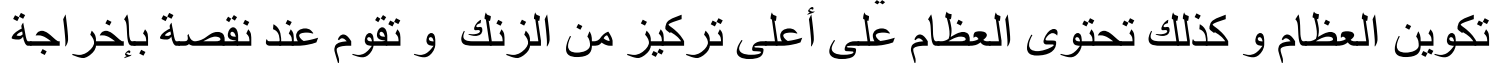

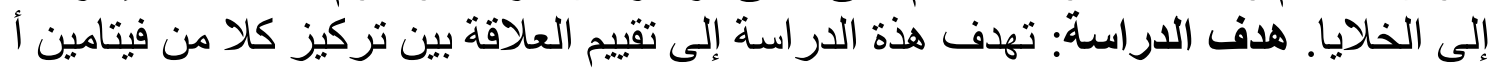

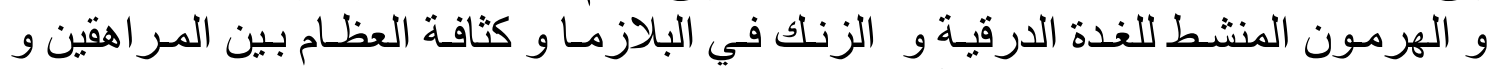

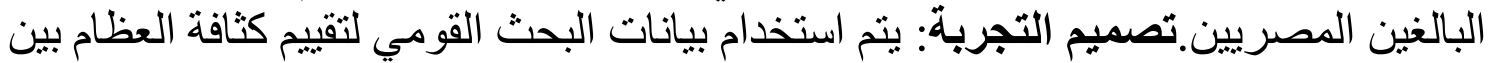

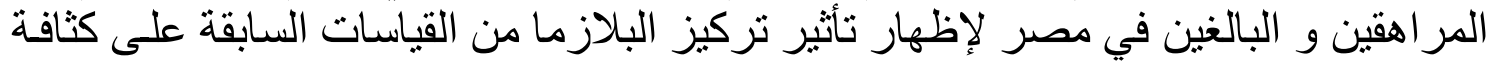

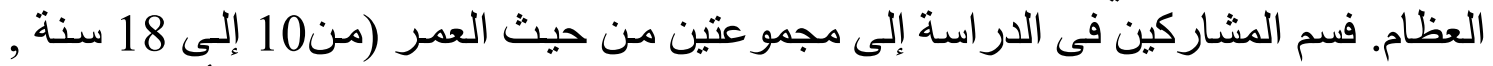

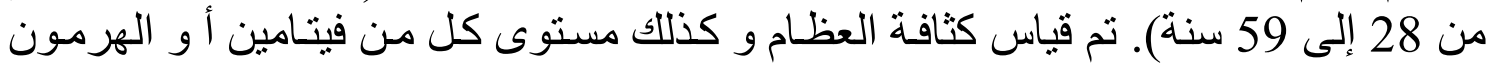

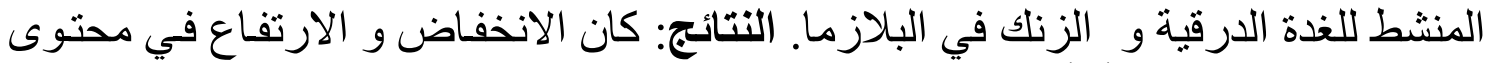

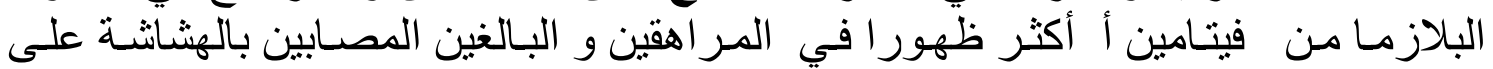

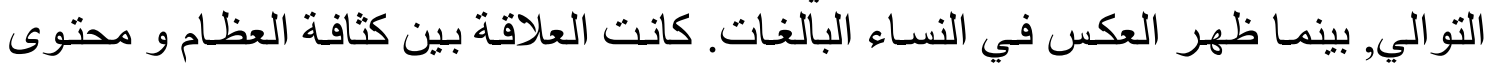

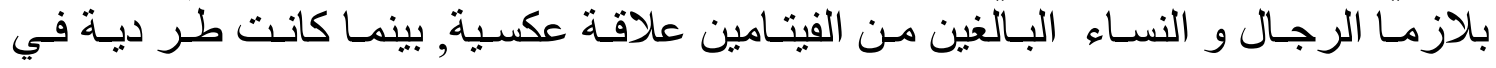

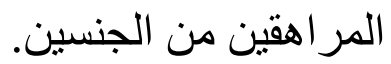

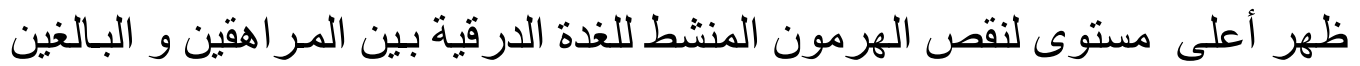

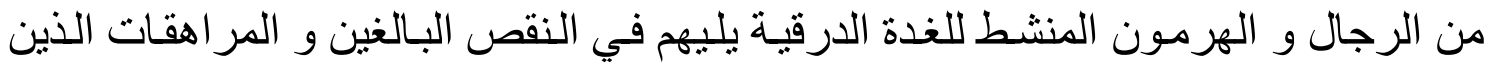

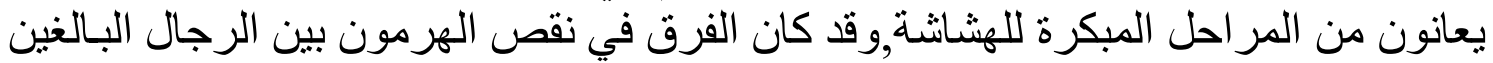

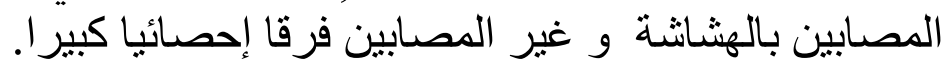

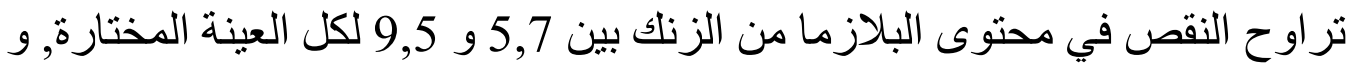

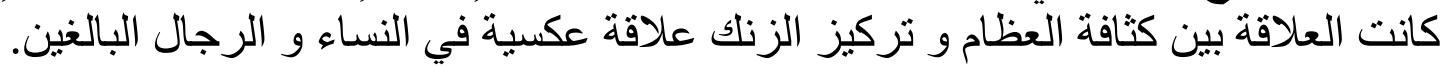

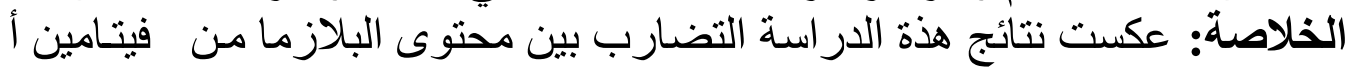

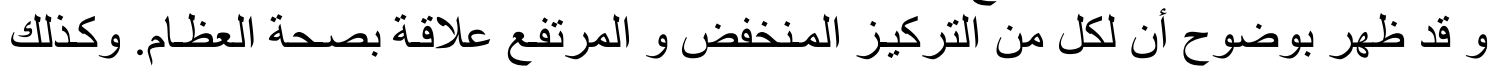

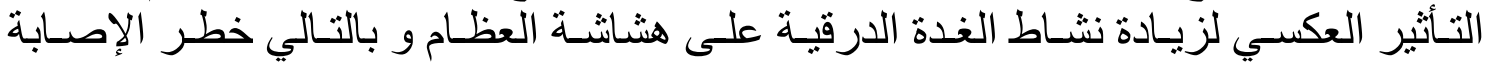
بالكسور . كما ظهرت العلاقة العكسية بين نقص الزنلك و الهشاثة بين الرجات الرال البالغين. 